\title{
LXXVIII. An account of a series of observations made on the distance of the sun and moon for determining the longitude of the place of observation, with remarks on the best method of making such observations, with their calculation, deductions, \&c.
}

\section{Firminger}

To cite this article: M. Firminger (1812) LXXVIII. An account of a series of observations made on the distance of the sun and moon for determining the longitude of the place of observation, with remarks on the best method of making such observations, with their calculation, deductions, \&c. , Philosophical Magazine Series 1, 40:176, 444-453, DOI: $10.1080 / 14786441208638266$

To link to this article: http://dx.doi.org/10.1080/14786441208638266

Published online: 27 Jul 2009.

Submit your article to this journal ¿

山 Article views: 2 
of any utility whatever. The author's papers in the Philosophical Transactions are hitherto free from this affectation, and we hope he will see the propriety of using only pure potash in future in these Elements. Sir Humphry is no less distinguished for the sublimity and beauty of his language than for his unparalleled discoveries : cousequently his example in such a case must naturally become the jus et norma loquendi.

We understand that translations of this volume into Portuguese and Spanish have already been undertaken by gentlemen very well qualified for the arduous task.

LXXVIII. An Account of a Series of Observations made on the Distance of the Sun and Moon for determining the Longilude of the Place of Observation, with Remarks on the best Method of making such Observations, with their Calculation, Deductións, \&ீc. By Mr. Firminger, late Assistant at the Royal Observatory, Greenwich.

$I_{T}$ being generally understood, that to determine the longitude of a place by the lunar observations, it is requisite to have three separate observers, viz. one to observe the moon's altitude, another the sun's, and a third to take the distance between the limbs of the sun and moon, or the moon and a star, I was induced to make a set of observations for determining the longitude of my place without any such assistance, it having frequently occurred to me that a series of observations migbt be made by only one observer, which would require but little additional labour in the calculation to that which is necessary when three separate observers are employed, and the result of the trial has fully confirmed my conjecture.

The following observations, from whence this conclusion was drawn, have not the best possible arrangement; it was readily seen in making the calculation, that much of the trouble of reduction might have been avoided by a different method of taking the observations; but what has been done will, it is hoped, be sufficient to show the value of the means which have been employed.

The weather at the time of the year when these observations were made, is but seldom favourable in London, and it was owing chiefly to this circumstance that different sets of observations on the same day were taken, and which it was intended to repeat till the number of independent sets amounted to ten, by taking two or three sets each day; but the fine weather 
weather did not continue sufficiently long for this purpose; nor has an opportunity offered since the period at which these observations were made to repeat them. The sets were four in number; two were taken on the 25th of October, and the remaining two on the 27th. The sun's and moon's altitude were taken from an artificial horizon, and the time at each observation noticed from a common horizontal watch showing seconds : great accuracy was not regarded in taking the moon's altitude, nor indeed of the sun's, accept that set from whence the time was to be computed, for a small error in the observed altitude cannot materially affect the correction to be applied in reducing the apparent to the true distance: great care however should be observed in noticing the moment when the distance is completed, as, whatever error is committed here, will appear in the longitude, that being deduced by a comparison of the time at Greenwich, given by the observed distance compared with the distance deduced from the Nautical Almanac, and the time inferred from the sun's observed altitude.

The method which I should advise would he, first, to take a single observation of the altitude of the moon's enlightened limb, then one of the sun's lower limb*, and when these have been completed, take with the greatest care five distances at least of the proper limbs of the sun and moon. When these are finished, take another altitude of the sun, then one of the moon; these four altitudes of the sun and moon will be sufficient for clearing the distance; and if they are taken at nearly equal intervals of time before and after the time at distance, it will be only necessary to take a mean of each two corresponding altitudes, which will very nearly correspond to the apparent altitudes when the distance was taken; but a set of observations of the altitude of the proper limb of the sun should now be taken, and the time noted down with the greatest care. These observations should not be less than five, because from them the apparent time at distance is to be inferred by a comparison with the watch. From this method of proceeding little difficulty occurs, or additional trouble to the usual method by three separate observers; and I am induced to think that it possesses many advantages over that method in point of accuracy, for in the latter case the whole is com-

* This applies equally to a star when that is uced instead of the sun, and is to be so understood in all cases here referred to. 
pleted by one ohserver; and if he has a good eye, and is careful in making his different sets of observations, it is more than probable that the whole will be conducted with much greater accuracy than when three separate observers are einployed, as it seldom happens that each of the cobservers is equally correct and careful; and should it be discovered that the one who takes the sun's altitude is inaccurate, the whole deduction will be affected with that inaccuracy : nor indeed is it scarcely possible for each observer taking the altitudes to complete his obsert ntion at the sane time that the one who takes the distance has completed his; and the inaccuracy arising will be of considerable importance, should this happen to the observer who observes the object from whence the time is to be computed.

In the method I have adopted, the only inaccuracy affecting the observation arises from the altitudes of the bodies not increasing or decreasing uniformly: this, in the suin or a star, is of no importance if the observer is at all expert at making his observation, and in the moon the error will be too small generally to deserve notice. The watch by which the observations are made, should have a seconds hand, and ought not to vary nure than one minute in twenty-four hours; - a good horizontal or duplex watch will answer very well, and will allow time for the observer to take his final set of observations for determining the error of the watch without hurrying himself.

The deductions derived from a mean of the four sets of observations abrut to be enumerated, give the longitude of the place in time $38,9 \mathrm{sec}$. west of Greenwich; or in space $9^{\prime} 31^{\prime \prime}, 35$ west*. By a reference to the best maps of Iondon, it appears that the Polygon, Somers Town, is about $\mathbf{4 0 0}$ yards to the cast of St. James's Church, Piccadilly, and the longitude of this church is according to the trigonometrical survey, $8^{\prime} 5^{\prime \prime}$ west of Greenwich. The observations give the longitude of the Polygon, Somers Town, $1^{\prime} 26^{\prime \prime}, 35$ to the ivest of St. James's Church, or about one mile; this added to the distance that the Pulygon is to the east of St. James's Church, makes the whole error in longitude deduced from these observations about one mile and a quarter, which, taking into consideration the errors of observation, of the instruments, and of the lunar tabtes, will be found very small; and I am fully persuaded

\footnotetext{
- The observations werë taken near the Polygon.
} 
that had the number of ohservations been augmented to ten, and a mean of the results taken, a great part of the present crror would have been removed.

I shall conclude these deductions by remarking, that a complete set of observations similar to those I have here given may be taken in the space of a quarter of an hour, or twenty ininutes, by a singlc observer, and that they may be facilitated, and rendered a little more accurate, by the assistanice of some person to write down the observation at the time: this part of the business, indeed, any one may do, and $I$ am inclined to believe that under such circuinstances the grcatest error committed, will seldom exceed five miles, but will generally fall short of this distanice.

I have rectuced the apparent distance to the true by the method given in the supplement to the $3 \mathrm{~d}$ edition of the requisite Tables, a method both simple and expeditious, and so easy in practice that a child of eleven years of age of moderate capacity might in a short time be fully instructed to perform the calculation.

I cannot help remarking, that many attempts have been made, and are still makitg, to construct machines for the more easily determining the longitude at sea; and although I am far from wishing to discourdse any such attempts when conducted upon scientific principles, yet I am greatly surprised that the means of determining the longitude bv the lunar observations should even at this time be thought an operose task. 'The improvements in the lunar tables, in the construction of sextants, and in the inethod of reducing the apparent to the true distance, have been such as to ensure the observer, with even but a moderate degree of experience, an accuracy far greater than is ever required in nautical practice. It may be said, that the weather is ofteutimes too infavourable to determine the longitude by the lunar method, and that for several days in the month the moon is invisible, being too near the sun. Here the use of a good time-kecper would be of great advantage, as by it the longitude would be easily carried on between the opportunities which offer, to obtain distances of the sun and moon, or the moon and a star, and even a timc-keeper of very moderate performance would answer this purpose with sufficient accuracy for every nautical purpose : would it not therefore be of great advantage to the maritime department of this country to have young gentlemen designed for the service, of the sea, well educated on shore, both in the practice as well as theory of finding the longitude by the means here recommended? 
October 25, 1812,-The morning being very fine, the following observations of distances and altiludes were taken for finding the longitude:

N.B. $27^{\prime \prime}$ is to be added to all the observations to the 27 th inclusive.

F. M. S.

22.413 Time by watch. $42^{\circ} 36^{\prime}$ on $^{\prime \prime}$ Double alt. $D$ 's U.L.

22435 Ditto $\quad 974910$ Dist. nearest limbs, $\odot \&$ D

22474 Ditto 485550 Double altitude $\odot$ 's LL.

225723 Time by watch $37^{\prime} 38^{\prime \prime} 40$ Double alt. D's U. L.

2320 Ditto 2nd set 974000 Dist. nearest limbs $\odot$ \& $D$ $\begin{array}{lll}23 & 5 & 3\end{array}$

501400 Double alt. $\odot$ 's L. L.

H. M. s.

Oct. 27th. 204400

941140 Double alt. D's U.L.

204800

5020

Mean $\frac{5250}{205023}$

$7453 \quad 11$

$5150\}$ Dist. nearest limbs $\odot \&$

205500

$\begin{array}{lll}55 & 49\end{array}$

5640

Mean 205549.6 5110

745237

$\begin{array}{lll}31 \quad 5 & 30\end{array}$

$1540\}$ Double alt. $\odot$ 's L. L.

$21 \quad 0 \quad 8$

$\left.\begin{array}{rrrr}21 & 7 & 35 & 40 \\ 2 & 3 & 20 & 30\end{array}\right\}$ Double alt. D's U.L.

Mean $21 \quad 6 \quad 903713.3$

21531

76

744

Mean $\overline{2 1 \quad \longdiv { 6 7 }}$

$\begin{array}{lll}33 & 14 & 407\end{array}$

33 10 0 's L. L. double alt. 4120

$33 \quad 2943$

Second set $21 \quad 16 \quad 2$

871110 Double alt. D'B U. L.

$21 \quad 1923$

2016

Mean $\frac{2121}{212020}$

$7441 \quad 10$

$4100\}$ Dist. nearest limbs $\odot \&$ $4040\}$

$2153 \quad 31$

2414

$\frac{2455}{\frac{212413}{212638}} \cdot \frac{37}{365226}$

$\left.\begin{array}{rrr}36 & 44 & 50 \\ 52 & 20\end{array}\right\} \odot$ L. L. double alt.

Double alt. D's U. L. 
Calculation of the observations of the distances of the Moon's remote limb from the Sun, taken on October 25 th and following days.

Calculation of the First Set, taken October 25th, 1812.

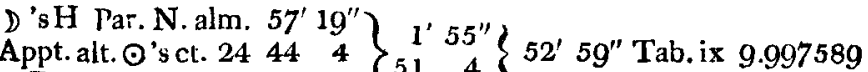

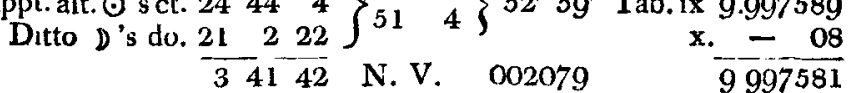

Dif. appt. alts. 982122 N. V. 1.145326

Dif. true alts. $\quad 24843 \quad$ N. V. 0.001204

$$
\begin{array}{lll}
\frac{1.143247}{1.136896} & \text { Log. } & 6.058140 \\
\hline \text { Log. } & 6.055721 \\
\hline
\end{array}
$$

True distance $9756 \quad 16 \quad$ N. V. $\overline{1.138100}$

$\odot$ 's L. L. $\frac{48^{\circ} 58^{\prime} 15^{\prime \prime}}{24287}$ Double alt.

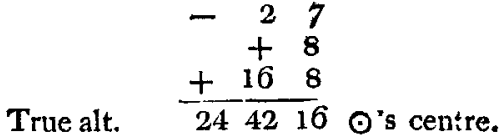

$\odot$ 's P. D. 102297 cosec. 0.0103938

Latitude $\quad \begin{array}{llllll}51 & 31 & 46 & \text { sec. } 0.2061312\end{array}$

Sum $\overline{178} \overline{439}$

Half sum $892134 \mathrm{cos} . \quad 8.0484251$

Remainder $643918 \mathrm{sin} .99560467$

$$
\begin{aligned}
& \begin{array}{l}
7^{\circ} 24^{\prime} 36^{\prime \prime} \\
05916 \frac{8}{48}
\end{array} \\
& 24 \\
& 2 3 \longdiv { 0 4 3 } \\
& \begin{array}{ll}
-\quad 359 & \text { Reduction to dist. } \\
225644 & \text { Appt. Time. }
\end{array}
\end{aligned}
$$

Distance per N.A. at $21^{\text {h }} 98^{\circ} 55^{\prime} 29^{\prime \prime}$

True distance

Distance per N. A. at $0 \quad 972439$

$$
\begin{array}{lll}
2970 & \text { P. L. } & 13050 \\
4828 & \text { P. L. } & \text { O } 5913 \\
1858 & \text { P. L. } & \text { H. M. S. } \\
\hline
\end{array}
$$

Time at Greenwich

21

Appt. time at place

225721

225644 of Observation.

Longirude $\quad 37 \mathrm{~W}$. fr. Greenwich.

Yol, 40. No. 176. Dec, 1812. 
Computation of the Second Set, taken October 25th.

D's h. par.

$57^{\prime} 19^{\prime \prime}\left\{1^{\prime} 51^{\prime \prime}\right\}^{53^{\prime} 22^{\prime \prime} \text { Tab. ix. } 9.997880}$

Appt.alt. D's ct. 183342

Ditto $\odot$ 's ct.

Diff. appt. alt.

64925

$\{5131\}$

Appt. dist.

$98 \quad 12$ 1

N. V.

$x$.

9.997872

6.055228

$\overline{6.053100}$

Diff. true alts. $\quad \begin{array}{llll}5 & 56 & 3\end{array}$

True dist.

974656

$\frac{1.142687}{1.135604}$

2] $50^{\circ} 14^{\prime} 27^{\prime \prime}$ Double alt. $\odot$ 's L. L.

$-22$

$+8$

$\begin{array}{r}+168 \\ \hline 252128\end{array}$

1022912 cosec. 0.0103938

$\begin{array}{lllll}513146 & \text { sec, } 0.2061312\end{array}$

2] $\longdiv { 1 7 9 2 2 2 6 }$

$8941 \quad 13$ cos. 7.7374966

641945 sine 9.9548682

2] 17.9058898

$5^{\circ} 9^{\prime} 57^{\prime \prime}$ s 8.9544449

$041 \overline{936}$

$23 \quad 184024$

\begin{tabular}{ll}
-33 & Reduction to time at dist. \\
\hline 231537,4 & Appt. time at Observation.
\end{tabular}

October 25th, at $21 \mathrm{~h} 985529$ Per N. Almanac dist.

Ditto at Obs.

Ditto at oh.

974656

972439 P. L. 2970

13050 P. L. 4193

1833 P. L. $\overline{1223}$

21550

H. M. $\mathrm{s}$.

21550

21

231550

$23 \quad 15 \quad 37,4$

Longitude 6 W. from Greenwich. 
Computation of the First Set, observed Octoler 27, 1812.

's H. par. $\left.\left.55^{\prime} 47^{\prime \prime}\right\} 3^{\prime} 15^{\prime \prime}\right\} 40^{\prime} 58^{\prime \prime}$ Tab. ix. 9.995103

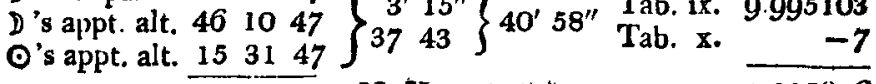

9.995096

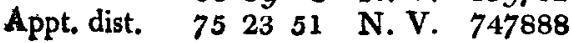

Dif true alt. $31 \quad 1958$

145838

True dist. $\quad 752123$

747195

O's alt. observed 2] $\frac{31 \quad 15 \quad 57}{153758}$

$+167.8$

$+8.0$

O's true alt.

$\frac{323}{155051}$

O's P D.

10384 cosec. $\quad 0.0115126$

Latitude

513146 sec. $\quad 0.2061312$

Sum $\quad 1 \overline{703041}$

Half sum

Remainder

$$
\begin{aligned}
& \begin{array}{rr}
24^{20} 5647 & 87 \\
2473416 & \text { s } 9.10532683 \\
\hline
\end{array} \\
& \text { s } 9.9713264
\end{aligned}
$$

5.779132

October 27, at 21 н $75^{\circ} 25^{\prime} 2^{\prime \prime}$ Dist. per N. Almanac

At Obser.

28th noon

$\begin{array}{lllll}75 & 21 & 23 & \text { Ditto }\end{array}$

$\begin{array}{lllll}73 & 59 & 35 & \text { Ditto }\end{array}$

$12527 \quad$ P. L. $\quad 3236$

339 P. L. 1.6930

$7^{\prime} 42 \quad$ P. L. $\overline{1.36 \overline{94}}$

9 h.

$\frac{9}{972}$ Time at Greenwich

$\begin{array}{llll}9 & 7 & 0 & \text { Appt. time at place of observation }\end{array}$

Iongitude W. from Greenwich. 
Reduction of the Second Set of Olservations taken on Oct. 27, 1812.

D's H. Par. $55^{\prime} 46^{\prime \prime}$

$\left.\left.\begin{array}{llll}\text { Appt. alt. } 0 & 43 & 6 & 16 \\ \text { Do. } \quad 0 & 38 & 11 & 46\end{array}\right\} \begin{array}{ccc}39^{\prime} & 41^{\prime \prime} \\ 2 & 44\end{array}\right\} 4225$

9.995372

381146
245430 N. V. 093016

$\frac{-}{9995365}$ 751244 N. V. 744760

$5 \cdot 814078$

$$
\frac{\overline{651744}}{644827}
$$

$5 \cdot 809443$

$\odot$ 's True Alt.

253655

098283

True dist. $75^{\circ} 6^{\prime} 52^{\prime \prime} \quad \overline{743110}$

Double Alt. $\odot$ 's LL 2) 365254

$\overline{182627}$

$+168$

$-249$

O's P. D.

$\frac{+8}{183954}$

Latitude

10384 cosec. 00115126

Appt. Time 513146 sec 0.2061312

2) $\overline{1731944}$ c 8.7648002

863952 s 99671642

675958

2) 18.9496082

$17 \quad 2142$

s $9 \cdot 4748041$

8

$2^{5} \overline{18} \overline{5336}$

24

$\overline{2141} \overline{624}$

Distance at

Obser.

28 th noon -353 reduction to time at distance.

Time at Greenwich 21 . $75^{\circ} 25^{\prime} 2^{\prime \prime}$ per Nautical Almanac. $\begin{array}{lll}75 & 652 \\ 7 & 59 & \end{array}$

\begin{tabular}{llll}
73 & 59 & 38 \\
\hline
\end{tabular}

$1 \longdiv { 2 5 2 7 }$ PL 3236

o 1810 PL 9960

$0^{\text {h }} 3817$ PL $672 \overrightarrow{4}$

21

Appt. Time at Place

$\overline{213817}$

$\begin{array}{llll}21 & 37 & 13\end{array}$

Longitude from Greenwich $14 \mathrm{~W}$. 
By collecting together the different results given above, they will stand as follows :

M. 5 .

Oct. 25th. 1st Set Obs. O 37 W. 2 Do. $012,6 \mathrm{~W}$.

Oct. 27 th. 1st Set Do. 042 W. 2 Do. 14 W.

4) $2 \overline{35,6}$

Mean from Greenwich $38,9 \mathrm{~W}$.

Hence the Longitude derived from the above observations comes out 38,9 s. in time West of Greenwich, or equal to $9^{\prime} 31,35^{\prime \prime}$ in space. The reason for giving the calculations at full length has been merely to show their simplicity; and should they tend to induce other persons interested in the determination of this useful problem to repeat them, the author's intentions will be answered. His object has been in this instance directed only to an endeavour to facilitate the acquirement of the method of determining the Longitude by a means both simple and certain.

Somers Town, Dec. 27, 1812.

\section{Proceedings of Learned Societies.}

ROYAL SOCIETY.

Nov. 26. The Croonian Lecture, by Dr. Wollaston, was read. It was an unusually brief lecture, and treated only on the integral molecules of crystals. Dr. W., improving an ingenious speculation of Dr. Hooke, assumed the principle, that the original molecules of matter are globular; and with these globes, he very satisfactorily showed how many of the primitive forms of crystals might arise from their disposition. He acknowledged that the assumption was perfectly gratuitous; but alleged, that at present there is no other mode of accounting for the tetrahedral and other forms of crystals.

Saturday the 3oth November, being St. Andrew's day, the Royal Society held their annual meeting, at their apartments in Somerset Place, for the choice of a Council and Officers for the year ensuing, when the following gentlemen were elected:

Of the old Council :-The right hon. Sir Joseph Banks, Bart. K. B. ; Sir Charles Blagden, Knt. ; Samuel Goodenough, Lord Bishop of Carlisle; Anthony Carlisle, Esq.; Sir Humphry Davy, Knt.; Samuel Lysons, Esq. ; Joseph Ff 3 